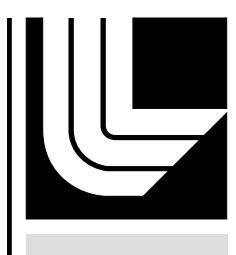

LAW RENCE LIVERMORE NATIO N A L LABORATORY

Seismic Monitoring for the United Arab Emirates

Arthur Rodgers, Keith Nakanishi

April 11, 2005 
This document was prepared as an account of work sponsored by an agency of the United States Government. Neither the United States Government nor the University of California nor any of their employees, makes any warranty, express or implied, or assumes any legal liability or responsibility for the accuracy, completeness, or usefulness of any information, apparatus, product, or process disclosed, or represents that its use would not infringe privately owned rights. Reference herein to any specific commercial product, process, or service by trade name, trademark, manufacturer, or otherwise, does not necessarily constitute or imply its endorsement, recommendation, or favoring by the United States Government or the University of California. The views and opinions of authors expressed herein do not necessarily state or reflect those of the United States Government or the University of California, and shall not be used for advertising or product endorsement purposes.

This work was performed under the auspices of the U.S. Department of Energy by University of California, Lawrence Livermore National Laboratory under Contract W-7405-Eng-48. 


\title{
Seismic Monitoring for the United Arab Emirates
}

\author{
Arthur Rodgers and Keith Nakanishi \\ Earth Sciences Division \\ Lawrence Livermore National Laboratory, Livermore, CA 94551 \\ April 11, 2005
}

\section{Executive Summary}

There is potential for earthquakes in the United Arab Emirates and in the Zagros mountains to cause structural damage and pose a threat to safety of people. Damaging effects from earthquakes can be mitigated by knowledge of the location and size of earthquakes, effects on construction, and monitoring these effects over time. Although a general idea of seismicity in the UAE may be determined with data from global seismic networks, these global networks do not have the sensitivity to record smaller seismic events and do not have the necessary accuracy to locate the events. A National Seismic Monitoring Observatory is needed for the UAE that consists of a modern seismic network and a multidisciplinary staff that can analyze and interpret the data from the network. A seismic network is essential to locate earthquakes, determine event magnitudes, identify active faults and measure ground motions from earthquakes. Such a network can provide the data necessary for a reliable seismic hazard assessment in the UAE. The National Seismic Monitoring Observatory would ideally be situated at a university that would provide access to the wide range of disciplines needed in operating the network and providing expertise in analysis and interpretation.

\section{Introduction}

The motion of tectonic plates on the earth's surface is marked most dramatically by earthquakes that occur along the plate boundaries. The UAE is situated in the Arabian tectonic plate (Figure 1). Near the UAE, earthquakes occur along the collision of the Arabian and Eurasian Plates that forms the Zagros Mountains of Iran, one of the most seismically active regions in the world. Large (greater than magnitude 5.0) earthquakes in the Zagros are common and larger events (say, magnitude 6.5 can be expected). These earthquakes can occur within $100 \mathrm{~km}$ of the UAE and pose a potential hazard to property and lives.

Earthquakes can also strike in the UAE as evidenced by the damaging earthquakes near Masafi in early 2002. The largest event in this series was a magnitude 5.1 that occurred on March 11, 2002 and was detected and located by global seismic networks, such as the United States Geologic Survey (USGS) National Earthquake Information Center (NEIC) and the International Seismological Centre (ISC). Another smaller event (magnitude 4.0) occurred in January. Several smaller events were felt during the months before and after the main event. In October 2004, another earthquake struck near Dibba. Only relatively large earthquakes can be detected and located by seismic stations at distances greater than several hundred kilometers from the event, because seismic energy weakens with distance from the source. Furthermore, the precise location of seismic 
events cannot be known with distant observations unless one has exceptionally accurate models of the seismic wave speed structure of the earth. While seismologists have approximate models of sub-surface earth structure, detailed accurate structure is not known. Because of these factors, the only way to have reliable knowledge of all earthquake activity in the UAE is to deploy a network of seismic stations that can continuously measure ground motions, including motions from very small earthquakes. Monitoring small earthquakes is essential because frequent small earthquakes can indicate the likelihood of larger earthquakes. Also, the locations of smaller earthquakes indicate which faults are active and are likely to have larger earthquakes. In order to obtain an accurate and comprehensive evaluation of seismic activity in the UAE, a network of stations located in the UAE is needed.

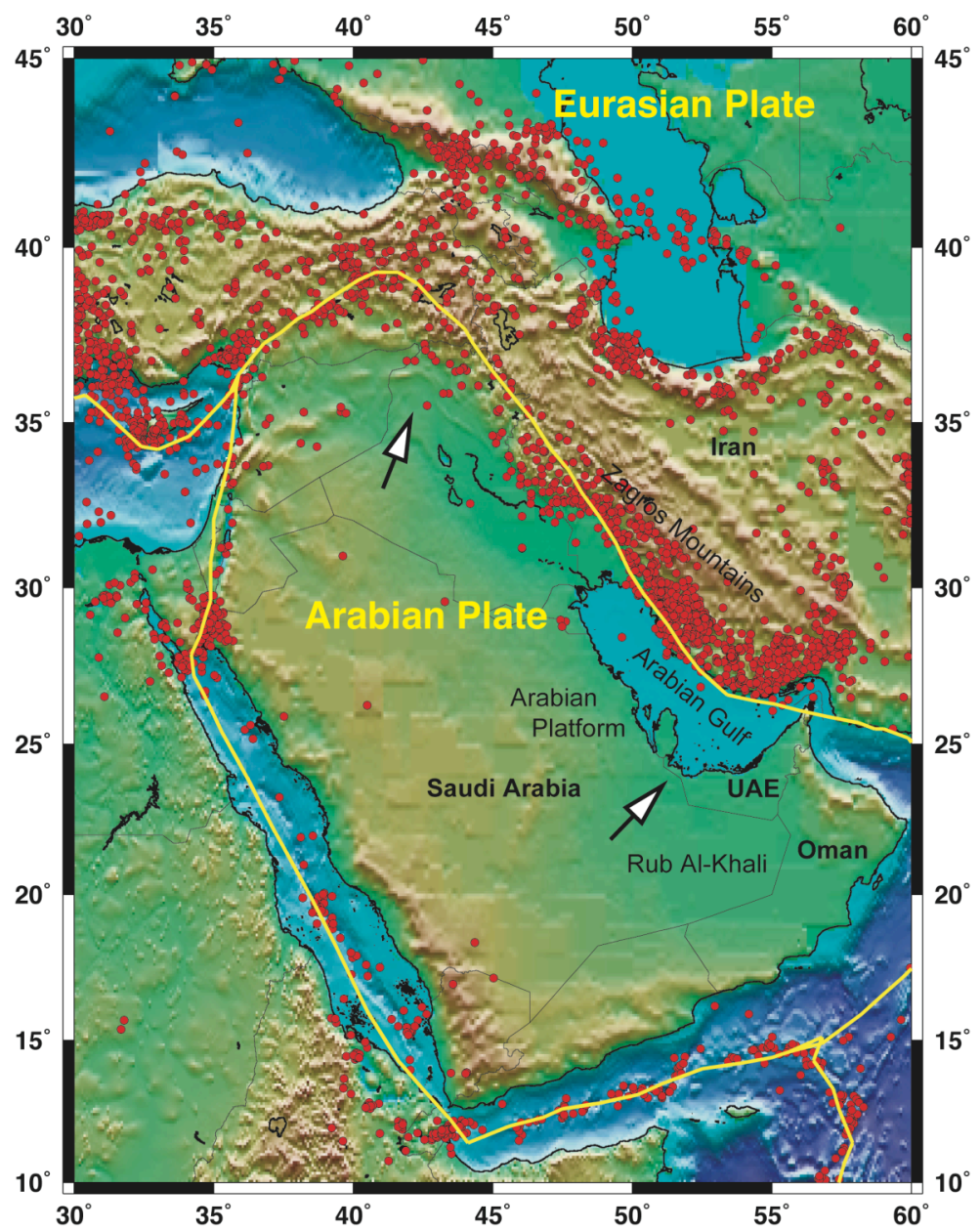

Figure 1. Map of earthquakes (red circles) in and around the Arabian Peninsula. Northeastward motion of the Arabian Plate leads to the seismic activity along the Zagros Mountains near the UAE.

\section{A National Seismic Monitoring Observatory}


Damage from earthquakes can cause loss of life, injuries and severe damage to buildings and industrial facilities. A National Seismic Monitoring Observatory would combine expertise and data and provide the government with information on earthquake monitoring and research. This Observatory can provide the government with the necessary technical consultations for monitoring earthquakes and providing technical input on seismic hazards and building codes. Furthermore, such an observatory can provide the government and public with earthquake alerts and educational materials to promote earthquake awareness.

\section{Operational Organization}

Earthquake science is a dynamic and multidisciplinary enterprise, and requires expertise from seismologists, geologists, engineers, computer programmers and public policy makers. The operation of a seismic network involves research and development and the multidisciplinary technical skills including electronics engineers, who must maintain communications equipment, computer programmers and system administrators who must maintain computer hardware and software, and of course seismologists who must perform routine data processing to determine locations and magnitudes of events. Earthquake hazard assessment requires evaluation by civil engineers and discussions with public policy makers to implement the results.

Most seismic observatories are operated with funding from the national government however are closely aligned with universities or research institutions to take advantage of the multidisciplinary research required. The research staff members are university faculty with the operations part having responsibilities for reporting earthquake activity to the government. This is the model of most observatories in the United States which are operated by universities such as the University of California at Berkeley, California Institute of Technology, Columbia University and Saint Louis University. Results are transmitted to the national earthquake authority at the United States Geological Survey, however the primary operations and research responsibility lies with the university. Oman has a similar model, with the Earthquake Monitoring Center (EMC) at Sultan Qaboos University. The EMC supports research activities done by university faculty, graduate students and visiting scholars and receives funding directly from the government and has a responsibility to report earthquake activity directly to the government.

\section{A National Seismic Network}

Key to the seismic observatory is a national seismic network consisting of several components. There is the seismic recording, communications and processing equipment (hardware). There is computer software that can automate many of the routine processing of the data. Lastly, but most importantly, there are the personnel to make all the hardware and software function properly and perform the research to understand and report the earthquakes and ground motions. 
Hardware consists of the seismometers to measure ground motions at broadly distributed stations, convert ground motions to electric signals, digitize them and transmit them to a single data center for analysis. At the data center (within the earthquake center) modern computer systems can collect these data and process them to detect and locate seismic events as well as estimate locations and magnitudes. The advances in computer hardware and software over the last few years have lead to great advances in earthquake monitoring processing hardware and software. Systems are now available to process great volumes of data with high reliability and very little human analyst interaction. Such systems can be costly initially, but can be economically efficient in the long run due to lower operating costs. Costs must be weighed with long-term operating budgets and reliability in mind.

\section{Types of Seismic Monitoring Instrumentation}

There are two major types of seismic instrumentation: seismic (weak motion) and strong motion instruments. Weak motion instruments are generally used to detect and locate seismic events. They are very sensitive and designed to continuously record small ground motions from both small (say less than magnitude 3.5) local earthquakes and large (say greater than magnitude 5.0) distant earthquakes. These instruments generally record ground velocity. Typically weak motion stations are deployed on hard rock away from natural (e.g. ocean waves, wind) and man-made noise sources (e.g. mining operations, roads, industrial facilities). Digital waveform data are broadcast to a central data center for analysis with data from all stations.

Strong motion stations are designed to record large ground motions from large nearby earthquakes. Typically, these stations act in a so-called "triggered" mode, only saving data for periods where the ground motions exceed a pre-set threshold. These instruments typically record ground or building accelerations. Strong motions instruments are deployed near known active faults and/or in buildings and engineering structures. Usually strong motions stations are deployed in or near structures (e.g. buildings, bridges, industrial facilities) to study the response to earthquake motions.

Both types of instrumentation are needed to characterize the seismicity in a country. Weak motion will record seismic signals from local and regional seismic events and is needed to geophysically characterize seismic activity, location of faults in the earth that may be active and produce earthquakes and also to investigate seismicity from the Zagros mountains. Strong motions instruments will measure the shaking of the ground in the vicinity of buildings, dams, bridges and other structures. This information is needed to give the best estimate of designs and construction practices needed for safe structures. Although large ground shaking is not expected, strong-motion instruments are needed to characterize the ground shaking in the unlikely event that these motions are observed.

\section{Proposal for a National Seismic Network for the UAE}

Given the limited knowledge of earthquakes in the UAE, it necessary to build a national seismic network and lay the foundation for earthquake research in the country. In this 
section we outline specific plans for a national network, including potential station locations. Because we do not expect large earthquakes to occur frequently in the UAE, a weak motion network is needed in order to define active faults within the UAE and build a catalog of earthquake data for seismic hazard assessment. This would provide valuable information for future investigations. A small network of strong motion instruments can be placed in cities near critical structures such as tall buildings, power plants, dams, and bridges to provide data for design and construction practices.

\section{Site Selection Issues}

Weak motion stations should be distributed to broadly cover the expected earthquake faults and seismogenic zones. The reliability of event locations depends on how well the event is surrounded by stations of the network, so it is important that stations be distributed as broadly as possible. Unfortunately the desired distribution of stations can be prohibited by geography, such as coastlines, unfavorable geology (such as sand), impenetrable mountains and/or national boundaries.

The selection of site locations for seismic stations involves the consideration of several factors. These factors often involve trade-offs between the logistical convenience and technical performance of the network. Weak motion stations should be deployed away from cities, roads and coastlines in order to minimize noise levels. The instruments should be emplaced below the surface in order to shield them from variations in temperature and minimize wind noise. The desire to locate stations away from cities results in logistical challenges to communications systems. It is imperative that reliable communications exist between remote stations and the central data center. Modern remote communications systems rely on line-of-sight radio telemetry or VSAT satellite communications. Mobile phone communication is reliable, but prohibitively expensive.

\section{Proposed Site Locations}

Considering the known geology of the UAE and the constraints imposed by the geology, a plan could be developed for stations locations in a national seismic network. Mainly, the sedimentary (sand) deposits of the eastern majority of the country (Abu Dhabi Emirate) offer few good locations for stations. Fortunately this difficult could be offset by the likelihood that this region is seismically less active than the mountainous northern and western emirates.

Based on our studies of population density and geology, we would propose a seismic network of weak and string motion stations configure as shown in Figure 2. 


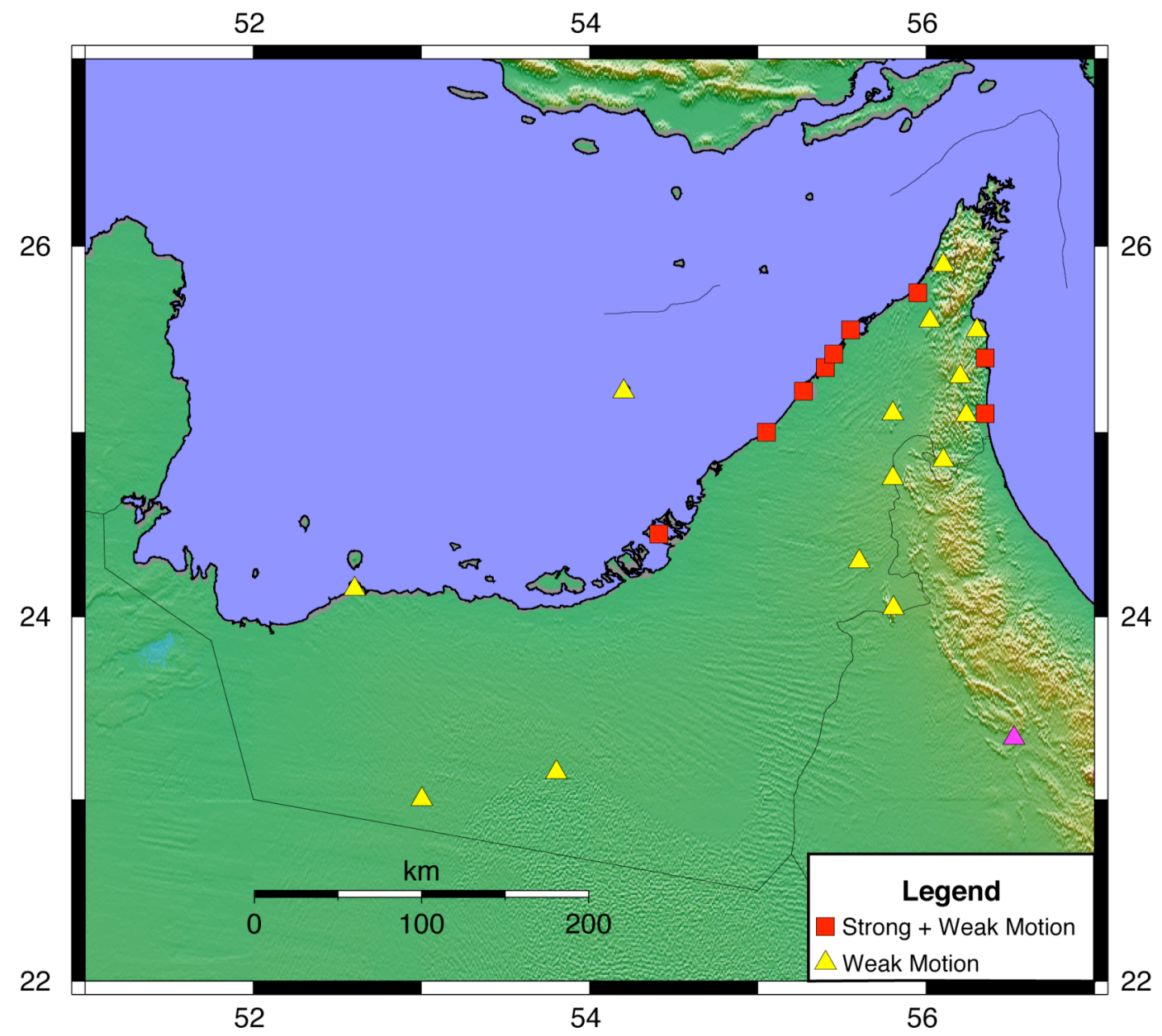

Figure 2. Notional configuration of a seismic network in the United Arab Emirates. The network would consist of weak motion (yellow triangles) and strong motion (red squares) sites. 